Biochimica et Biophysica Acta, 597 (1980) 155-165

(C) Elsevier/North-Holland Biomedical Press

BBA 78628

\title{
REDUCED LATERAL MOBILITY OF A FLUORESCENT LIPID PROBE IN CHOLESTEROL-DEPLETED ERYTHROCYTE MEMBRANE
}

\author{
NANCY L. THOMPSON and DANIEL AXELROD \\ Biophysics Research Division and Department of Physics, University of Michigan, \\ Ann Arbor, MI 48109 (U.S.A.)
}

(Received March 26th, 1979)

(Revised manuscript received August 22nd, 1979)

Key words: Fluorescent probe; Cholesterol depletion; Mobility; (Erythrocyte membrane)

\section{Summary}

The effect of cholesterol depletion of the human erythrocyte membrane on the lateral diffusion rate of a fluorescent lipid probe is reported. At low temperatures $\left(-5\right.$ to $\left.5^{\circ} \mathrm{C}\right)$, the diffusion of the probe is $50 \%$ slower in the cholesterol-depleted membrane than in non-depleted membrane. At high temperatures $\left(30\right.$ to $\left.40^{\circ} \mathrm{C}\right)$, probe mobility is not affected by cholesterol depletion. These results suggest that cholesterol suppresses aspects of phospholipid phase changes in animal cells in a manner consistent with its behavior in artificial bilayers and multilayers.

Whole erythrocytes were depleted of $30-50 \%$ of their cholesterol by incubation with a sonicated dispersion of dipalmitoyl phosphatidylcholine. Cells were then labeled with $3,3^{\prime}$-dioctadecylindocarbocyanine (diI), a phospholipid-like fluorescent dye, and hemolyzed into spherical ghosts. The rate of lateral motion of diI was measured by observing the fluorescence recovery after local photobleaching with a focused laser spot.

The diffusion rate of the lipid probe in both control and cholesterol-depleted erythrocyte membrane is substantially smaller than in any cell or model membrane previously measured.

\section{Introduction}

Lipid mobility in biological cell membranes has been correlated with certain biologically significant properties, e.g., permeability [1], immunochemistry

Abbreviation: diI, 3,3'-dioctadecylindocarbocyanine. 
[2], temperature adaptation [3,4], embryonic muscle fusion [5], egg fertilization [6,7], and enzyme activity [8]. These correlations between lipid mobility and biological functions, although not necessarily causative, spur interest in the factors which determine lipid mobility in both cell membranes and model lipid systems. One of these factors affecting mobility in a phospholipid bilayer appears to be cholesterol content. In general, cholesterol has a 'solidifying' effect at high temperatures and a 'fluidizing' effect at low temperatures [9].

The term lipid mobility generalizes many aspects of molecular motion, not all of which are directly related to each other or to the same biological activity. Lateral diffusion is one aspect of mobility for which the effect of cholesterol has been studied relatively little, and only in model systems [10-13]. We discuss here the effect of cholesterol depletion of erythrocyte membranes upon the lateral diffusion of a membrane-bound fluorescent lipid probe.

Whole human erythrocytes were depleted of $30-50 \%$ of their cholesterol by incubation with a sonicated dispersion of dipalmitoyl phosphatidylcholine [14-17]. After cholesterol depletion, cells were labeled with the fluorescent probe 3,3'-dioctadecylindocarbocyanine [18]. Carbocyanine dyes have been used previously as probes of lateral motion in model $[18,19]$ and biological [20-24] membranes. diI orients in the human erythrocyte membrane with its conjugated bridge parallel to the surface of the cell [25] and its two long acyl chains presumably parallel to those of the phospholipids. We quantitatively measured the lateral diffusion rate of diI by monitoring the fluorescence recovery after local photobleaching with a focused laser beam [26].

\section{Methods and Materials}

Cholesterol depletion. Erythrocyte cells were depleted of cholesterol by a method similar to that of Grunze and Deuticke [16]. Whole human blood was drawn and stored at $4^{\circ} \mathrm{C}$ for no more than $48 \mathrm{~h}$ with either EDTA, heparin, or citrate as an anticoagulant. $4-8 \mathrm{ml}$ of blood were washed three times at $1200 \times \mathrm{g}$ for $5 \mathrm{~min}$ in several volumes of isotonic phosphate buffer $(140 \mathrm{mM}$ $\mathrm{NaCl}, 45 \mathrm{mM}$ sucrose, $10 \mathrm{mM}$ sodium phosphate, $\mathrm{pH} 7.4$ ), and the buffy coat was removed. Cells were packed in a final centrifugation. An aqueous dispersion of liposomes was prepared by probe sonicating (Branson model S110, setting 4) $25 \mathrm{mg}$ of dipalmitoyl phosphatidylcholine (Sigma or Applied Science) in $2.5 \mathrm{ml}$ buffer containing $0.5 \%$ penicillin/streptomycin (Gibco No. $514)$ in an ice/water bath until clear (approximately $10 \mathrm{~min}$ ). Immediately following sonication, the lipid dispersion was added to approx. $0.4 \mathrm{ml}$ of packed washed red blood cells. The blood/liposome mixture was incubated at $37^{\circ} \mathrm{C}$ for $22-43 \mathrm{~h}$ with vigorous agitation. (Further incubation invariably led to rapid hemolysis of the cells.) After incubation, the cells were centrifuged and washed four times in several volumes of buffer with centrifugations at $1200 \times \mathrm{g}$ for $5 \mathrm{~min}$; this procedure pelleted the cells but not the liposomes. A small amount of cells was removed and stored at $4^{\circ} \mathrm{C}$ in $0.5 \mathrm{ml}$ Hank's balanced salt solution containing $\mathrm{Ca}^{2+}$ and $\mathrm{Mg}^{2+}$ (Gibco) for later photobleaching experiments, and the remaining cells were assayed for cholesterol content. Control cells were handled exactly in the same manner except that the $22-43 \mathrm{~h} 37^{\circ} \mathrm{C}$ incubation medium contained no liposomes. After hemolysis and fluorescent 
labeling (see later), microscopic examination showed that cholesterol-depleted erythrocyte ghosts were approximately $10 \%$ smaller in diameter than controls (see also Ref. 27).

Cholesterol assay. Lipids were extracted from the cells by the method of Rose and Oklander [28] as follows. After liposome incubation, $0.4 \mathrm{ml}$ of packed erythrocytes were mixed with $0.5 \mathrm{ml}$ distilled $\mathrm{H}_{2} \mathrm{O}$ for $15 \mathrm{~min}$, followed by addition of $5.5 \mathrm{ml}$ isopropranol for $1 \mathrm{~h}$, and finally followed by addition of $3.5 \mathrm{ml}$ chloroform for $1 \mathrm{~h}$. Occasional vortexing was performed throughout the period. The supernatant was separated from the heavy precipitate by centrifugation $(1200 \times \mathrm{g}, 30 \mathrm{~min})$, and the supernatant solvent was then evaporated under stream of nitrogen, leaving a dried film of extracted lipids.

Biochemical assay for cholesterol was performed according to the method of Searcy et al. [29]. The extracted lipid film was dissolved in $0.4 \mathrm{ml}$ acetone/ ethanol (1:1, by vol.). $3 \mathrm{ml}$ of $\mathrm{FeSO}_{4}$-saturated acetic acid was added, followed by $1 \mathrm{ml}$ of $\mathrm{H}_{2} \mathrm{SO}_{4}$, with gentle stirring. After $30 \mathrm{~min}$ the absorbance at $490 \mathrm{~nm}$ was measured on a spectrophotometer. Control experiments indicated that the absorbance was independent of phospholipid and blood serum proteins, and linearly related to the amount of cholesterol. The cholesterol assays, performed for both control and liposome-treated cells, showed that the liposome-treated cells were depleted of $33-51 \%$ of their cholesterol.

Fatty acid analysis. Possible alteration of membrane acyl composition by the liposome incubation was examined by gas-liquid chromatography. After sample incubation with liposomes or control incubation in liposome-free buffer, $0.3-1.5 \mathrm{ml}$ of packed erythrocytes (approx. $5 \cdot 10^{9}$ cells $/ \mathrm{ml}$, measured for each sample with a hemacytometer) were mixed with 1 vol. $(2-3 \mathrm{ml})$ of methanol followed by two vols. $(4-6 \mathrm{ml})$ of chloroform. The heavy hemoglobin precipitate was discarded by filtering the suspension through fluted Whatman No. 1 paper. To the solvent an amount of $\mathrm{H}_{2} \mathrm{O}$ equal to one quarter of the total volume was added and the mixture was then incubated at $4^{\circ} \mathrm{C}$ for $2-4 \mathrm{~h}$. The top water-soluble phase was removed and the bottom phase, containing the membrane lipids, was evaporated under a nitrogen stream. The lipids were redissolved in $1 \mathrm{ml}$ of $\mathrm{CH}_{3} \mathrm{OH} / 1 \mathrm{~N} \mathrm{H}_{2} \mathrm{SO}_{4}$ (36:1, by vol.) and incubated $12 \mathrm{~h}$ at $75^{\circ} \mathrm{C}$. After cooling, $1 \mathrm{ml}$ of hexane was added with shaking and the resultant top phase was collected for gas chromatographic analysis. The fatty acid content of the solutions was assayed on either a HewlittPackard 5840A GC with a 15\% DEGS/Chromasorb AWA (Supelco) column or a Varian 3700 GC with a $10 \%$ Silar 10-C/Chromasorb W-HP column.

Untreated erythrocytes had the following fatty acyl composition given as percentages of the total major fatty acyl constituents: $16: 0,27 \% ; 18: 0$, $22 \% ; 18: 1,23 \% ; 18: 2,14 \%$; chains higher in length or unsaturation, $14 \%$. Minor constituents, each less than $5 \%$ of the total fatty acyl composition, are not included here. Erythrocytes treated with liposomes for cholesterol depletion (at $37^{\circ} \mathrm{C}$ for more than $24 \mathrm{~h}$ ) showed what at first appeared to be major changes: $16: 0,56 \% ; 18: 0,15 \% ; 18: 1,15 \% ; 18: 2,5 \%$; higher chains, $8 \%$.

To futher characterize this apparent dramatic increase in palmitic acid $(16: 0)$ and decrease in all the others, we incubated erythrocytes with liposomes for only $15 \mathrm{~min}$ at $25^{\circ} \mathrm{C}$ instead of the usual $24-43 \mathrm{~h}$ at $37^{\circ} \mathrm{C}$. After this very brief incubation, the membranes displayed a fatty acyl composition 
closely paralleling that seen after the longer and higher temperature liposome treatment: $16: 0,54 \% ; 18: 0,15 \% ; 18: 1,16 \% ; 18: 2,8 \%$; higher chains, $8 \%$. The accuracy of all these percentages is about $\pm 2 \%$ of the total fatty acyl content. In terms of quantitative fatty acyl content per cell, palmitic acid increased by a factor of 2.7 for the short incubation and 2.8 for the long incubation, whereas the other major fatty acyls showed no significant changes at either incubation time. These results are interpreted in the Discussion.

Fluorescent labeling. Approximately $75 \mu \mathrm{l}$ of cholesterol-depleted or control packed cells were mixed with $0.5 \mathrm{ml}$ Hank's balanced salt solution and 0.5$2.5 \mu \mathrm{l}$ of diI $\mathrm{C}_{2} \mathrm{H}_{5} \mathrm{OH}$ solution $(0.5 \mathrm{mg} / \mathrm{ml}$ ) (a gift of Dr. Alan Waggoner). After incubation for $15 \mathrm{~min}$ at $37^{\circ} \mathrm{C}$, the cells in the suspension were hemolyzed into spherical ghosts by adding $0.5 \mathrm{ml}$ distilled $\mathrm{H}_{2} \mathrm{O}$ three times with gentle mixing after each addition. Hemolysis of erythrocytes into spherical ghosts was performed in order to reduce heating due to absorption of the $514 \mathrm{~nm}$ laser light by hemoglobin, and to enable focusing of the beam on one membrane surface only.

An upper bound for the average diI : lipid molar ratio in labeled cells was estimated to be less than $1: 600$. This ratio was determined by comparing, in a spectrofluorimeter, the diI fluorescence intensity from a labeled erythrocyte ghost suspension with that of a sonicated dispersion of diI : dipalmitoyl phosphatidylcholine (1:1000 molar ratio) of known diI concentration. Although the erythrocytes were washed several times in buffer after labeling and before hemolysis, fluorescence from diI vesicles persistently adhering to cells may have led to an overestimate of the membrane-incorporated diI concentration. No difference has been observed between unlabeled and diIlabeled intact erythrocytes in size, morphology, hemolytic fragility, or tendency towards clumping. In any one preparation, the diI labeling varies in brightness from cell to cell within a factor of two and occasionally as much as five. Cells with extremely bright or dim fluorescence were avoided in photobleaching experiments.

Photobleaching. The cells were drawn into a capillary microslide (Vitro Dynamics) in which they spontaneously adhered to the glass surface. The microslide was then mounted on a special holder coupled to a temperaturefeedback controlled thermoelectric cooler-heater (Bailey TS-2) on the stage of an inverted microscope (Leitz Diavert). Local fluorescence excitation was performed by focusing the $514 \mathrm{~nm}$ line of an argon ion laser (Lexel model 95-3) to a small spot by epi-illumination through a $100 \times, 1.25$ numerical aperture objective. A rectangular aperture in an image plane of the microscope, adjusted in size to be just larger than the image of the focused laser spot, helped to exclude out-of-focus fluorescence and stray light. Fluorescence intensity through the aperture was measured by an RCA $31034 \mathrm{~A}$ photomultiplier tube thermoelectrically cooled to $-30^{\circ} \mathrm{C}$. With this optical arrangement, a laser spot focused on the lower surface of the spherical ghost could be easily distinguished both visually and photometrically from a focus on the upper surface.

In the photobleaching technique, the local fluorescence is observed with a greatly attenuated laser power (approx. $0.5-1.0 \mu \mathrm{W}$ ). Local photobleaching is induced by a $3-6 \mathrm{~ms}$ duration flash of much higher power $(2-4 \mathrm{~mW})$ and 
then laser power is rapidly returned to its attenuated level for postbleach fluorescence observation. Subsequent lateral motion of unbleached fluorophore into the bleached region is observed as a fluorescence recovery. Prebleach and postbleach fluorescence is monitored by photon-counting electronics with a sample increment time of 5,10 or $20 \mathrm{~ms}$. In some experiments, signal averaging of up to five bleaches at a single location was performed on a Canberra model $\mathbf{8 1 0 0}$ digital multichannel scalar; in most experiments, the fluorescence recovery from one bleach was simply displayed on a storage oscilloscope screen and photographed for later measurement. Half-fluorescence recovery times were between $100 \mathrm{~ms}$ and $1000 \mathrm{~ms}$, much longer than the 3-6 ms bleaching flash. The depth of bleaching was $60-80 \%$. No significant bleaching by the attenuated laser beam occurred during fluorescence recovery.

Focused beam width. In order to calibrate diffusion contants on an absolute scale, one must measure a characteristic radius of the focused laser spot [26]. We visually focused the laser beam on a water-immersed glass coverslip uniformly coated with adsorbed diI. The position of focused spot was translated smoothly at speed $V_{0}=0.47 \mu \mathrm{m} / \mathrm{s}$ by driving the focusing lens on a motorized translator. During the slow translation of the spot, a $6 \mathrm{~ms}$ duration bright pulse photobleached a small region of the surface to a 'depth' equal to that used in erythrocyte experiments. After this brief bleaching, we then observed a 'flow' fluorescence recovery as the laser spot continued to translate at speed $V_{0}$. The half-recovery time $\tau_{1 / 2}$ is related to the $e^{-2}$ radius $w$ of the presumed Gaussian focused spot and the known scan rate $V_{0}$ by the formula $w \approx V_{0}$ $\tau_{1 / 2}$ (see Eqn. 20 of Ref. 26). For the 100X objective used in erythrocyte experiments, we thus obtained a beam radius $w=0.46 \pm 0.04 \mu \mathrm{m}$.

Spot size measurements by two other methods gave considerably smaller values; i.e., calculation from the measured half-angle of convergence of the beam [30], and scanning the spot past submicroscopic fluorescent beads. The discrepancy in calculated $w$ among these methods appears due to the rather extended non-Gaussian 'tails' of the intensity profile which induce considerable bleaching under the conditions of our experiments. Therefore, a beam measurement technique which observes the actual size of the bleached region, as does the flow recovery technique described above, should yield the most reliable result. Ideally, rigorous comparison of quantitative results obtained in different laboratories would be safest if all diffusion measurements were referred to results on some standard diffusing sample which would be measured on the same apparatus as the experiments. We have experimented with one possible standard, tetramethylrhodamine-labeled bovine serum albumin (Sigma, fatty acid free) in phosphate-buffered mixed $\mathrm{H}_{2} \mathrm{O}$ /glycerol solution ( $90 \%$ of wt. glycerol, final ionic strength $0.02 \mathrm{M}, \mathrm{pH} 7.0$ ). This fluorescent viscous solution is sandwiched between a microscope slide and a cover slip into a layer thinner than the depth of focus of the microscope objective. The known diffusion constant of bovine serum albumin under these ionic conditions in water [31] varies inversely with the tabulated temperature-dependent viscosity. From a calculation of the expected diffusion constant and the results of a photobleaching recovery experiment on this standard sample, we have been able to verify that our estimate of $w=0.46 \mu \mathrm{m}$ is correct to within $10 \%$.

Data analysis. Calculation of the lateral diffusion constant from experi- 
mental photobleaching parameters has been described previously [26]. Approximately $85-100 \%$ of the diI was found to be mobile; we report all diffusion constants $\bar{D}$ as a weighted average of the mobile and immobile contributions. Because several sets of experiments were done on different days with different blood samples and amounts of depletion, and perhaps slightly different optical alignments, we have multiplicatively normalized all $\bar{D}$ values so that the average diffusion constant of control cells at $30^{\circ} \mathrm{C}$ from each set of experiments is equal to the average of $30^{\circ} \mathrm{C}$ control cells over all experiments.

\section{Results}

In Fig. 1, the lateral diffusion constant $\bar{D}$ of diI in control and cholesteroldepleted erythrocyte membranes is shown as a function of temperature. Four conclusions are drawn: (1) $\bar{D}$ is on the order of $2 \cdot 10^{-9} \mathrm{~cm}^{2} / \mathrm{s}$; (2) at the lowest temperatures, $\bar{D}$ in cholesterol-depleted cells is slower by factor of 1.6 than in control cells; (3) at higher temperatures no significant difference of diffusion rate in the two types of cells is observed, and (4) between $-3^{\circ} \mathrm{C}$ and $40^{\circ} \mathrm{C}, \vec{D}$ is increased 2.5-fold for control cells and 4 -fold for cholesterol-depleted cells.

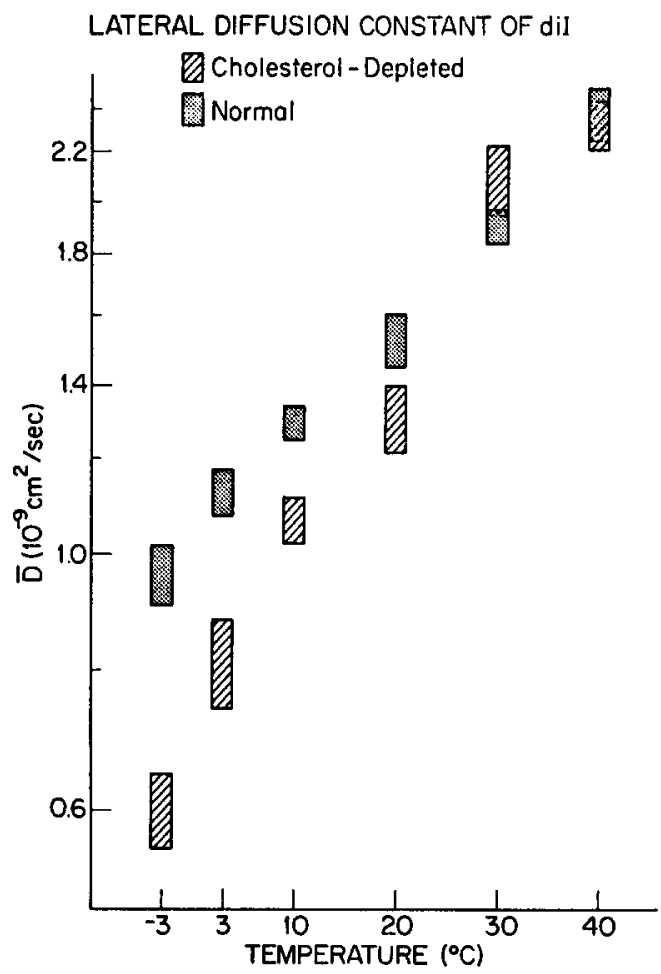

Fig. 1. Average diffusion constants of diI in control and cholesterol-depleted erythrocytes, as a function of temperature. Each bar is centered around the mean with its length indicating the range of the $S . E$. Means and S.E. were calculated from the following numbers of independent runs for each bar: $-3^{\circ} \mathrm{C}$, $43 ; 3^{\circ} \mathrm{C}, 31 ; 10^{\circ} \mathrm{C}, 40 ; 20^{\circ} \mathrm{C}, 42 ; 30^{\circ} \mathrm{C}, 60 ; 40^{\circ} \mathrm{C}, 39$. The accuracies of the temperature readings are $\pm 1^{\circ} \mathrm{C}$ for $10^{\circ} \mathrm{C}, 20^{\circ} \mathrm{C}, 30^{\circ} \mathrm{C}$ and $40^{\circ} \mathrm{C}, \pm 2^{\circ} \mathrm{C}$ for $+3^{\circ} \mathrm{C}$ and $\pm 3^{\circ} \mathrm{C}$ for $-3^{\circ} \mathrm{C}$. 
There was no difference in the average fraction of immobile diI (11\%) between control and cholesterol-depleted cells.

Experiments in which $\bar{D}$ was measured at higher temperatures $\left(30^{\circ} \mathrm{C}\right)$ both before and after lowering the temperature to $0-5^{\circ} \mathrm{C}$ indicated that the temperature dependence of $\bar{D}$ is reversible; $\bar{D}$ recovered to its original value in both types of cells.

\section{Discussion}

We have observed a reduced lateral diffusion rate of a membrane lipid probe at low temperatures in cholesterol-depleted human erythrocyte ghosts. This effect can be compared to previous results on model phospholipid systems. In oriented dimyristoyl lecithin/cholesterol multilayers, increasing the cholesterol content greatly increases the lateral diffusion rate of lipid probes below the phase transition and slightly decreases it above the phase transition $[10,12,13]$. Egg yolk lecithin in sonicated vesicles also shows a decrease in lateral diffusion upon addition of cholesterol at temperatures well above the phase transition [11]. Our low-temperature results with erythrocytes are consistent with the results on model systems. At higher temperatures, where the cholesterol effect in model systems is less pronounced, any small effect in erythrocytes might be obscured by data variance. One might conclude that, were it not for the presence of cholesterol, erythrocyte membrane lipids would be in a gel state for $T \leqslant 10^{\circ} \mathrm{C}$ and in a liquid-crystalline state at physiological temperatures. This conclusion is consistent with differential scanning calorimetry results on extracted erythrocytes lipids. Those results show a small endothermic peak at $T \approx 35^{\circ} \mathrm{C}$ in cholesterol-free extract [32] which is abolished in cholesterolcontaining total lipid extract $[32,33]$. Whether or not a clear phase transition would exist in cholesterol-free erythrocyte membrane somewhere between $10^{\circ} \mathrm{C}$ and physiological temperatures, we have shown that cholesterol does suppress temperature-dependent changes in the membrane's physical state.

The maximum cholesterol depletion of a human erythrocyte before hemolysis (approx. 50\% depletion) corresponds to a reduction in the cholesterol mol fraction from about 0.5 to 0.3 [34]. Since the erythrocyte membrane is a highly heterogeneous system in which some cholesterol might specifically associate with some proteins or partition unequally among regions of different lipid compositions and fluidities [35], the effective cholesterol mol concentration in some lipid regions could be significantly less than 0.3 . In comparison, pure phospholipid model systems exhibit well-defined phase transitions for cholesterol mol fractions of less than $0.25-0.35[1,12,32,35-37]$. Although lipid probe diffusion is more strongly temperature dependent in cholesteroldepleted erythrocyte membranes than in membranes of normal cholesterol content, development of a sharp phase transition should not necessarily be expected.

Somewhat analogously to this work on lateral mobility, previous experiments on rotational mobility of a fluorescent lipid probe in cholesterol-altered erythrocyte membrane show that cholesterol reduces the slope of the mobility vs. temperature curve [38]. However, the cholesterol effect in the two types of mobility is not identical. Increasing cholesterol appears to decrease rota- 
tional mobility at those high temperatures where lateral mobility is not affected and increasing cholesterol has only a small effect at those low temperatures where lateral mobility is increased.

It is unlikely that our results on erythrocytes can be explained by changes in membrane fatty acyl content or composition during vesicle incubation. Deliberate substantial fatty acyl alterations in cultured muscle cell membranes do not change diI mobility [20]. More directly relevant is evidence that substantial fatty acyl alterations do not occur during cholesterol depletion. Previous studies $[16,27,34,39]$ employing similar or identical techniques for cholesterol depletion of erythrocytes, have found no net change in the phosphorus content of the membrane, nor in the percent composition of the various phospholipids [27]. On the other hand, both our gas chromatographic results and recent tracer results of Giraud and Claret [40] show evidence of a rapid and significant net uptake of phospholipid by the erythrocytes, reaching a plateau within $15 \mathrm{~min}$ of incubation. The source of this contradiction in the literature remains unresolved. However, assuming net uptake does indeed occur (as we believe), it is important to determine whether it is true liposomeerythrocyte fusion, exchange of phospholipids, or stable surface adsorption [41]. The first two of these possibilities might affect the 'fluidity' properties of the erythrocyte membrane bilayer, whereas the third possibility would not have such an effect. Evidence in the literature argues against the first two possibilities. Martin and MacDonald [42] have obtained evidence against phosphatidylcholine liposome-erythrocyte fusion (although liposome-cell fusion may occur if liposomes containing stearylamine and lysophosphatidylcholine are used). Bloj and Zilversmit [43] find that phosphatidylcholine exchange between vesicles and erythrocyte is 13-fold slower than cholesterol exchange. Giraud and Claret [40], employing a 'non-exchangeable' lipid tracer, also find no significant phospholipid exchange. Therefore, the published evidence against fusion or exchange, as well as the great rapidity at low temperatures of the observed liposome uptake, strongly suggest stable surface adsorption of liposomes. To account for the uptake which we have observed, we calculate that stable liposome adsorption need involve only about $2 \%$ of the liposome available in the dispersion and therefore would not significantly affect the cholesterol assay results.

Since an estimate of true erythrocyte membrane alteration necessitates subtracting out the large amount of putative stable liposome adsorption, we must still allow for the possibility of some small changes in the mol fraction of various acyl chains relative to the total lipid. The most significant of these possible changes consistent with our gas chromatographic data could be an increase in mol fraction of palmitic acid $(16: 0)$. Assuming that the quantity of palmitic acid in the membrane remained unchanged during liposome treatment, its postincubation mol fraction would be $0.19 \pm 0.01$. The accuracy limit of our gas chromatography data ( $\pm 2 \%$ of the total fatty acyl content) allows for the possibility that the quantity of palmitic acid in the membrane might have increased slightly to a postincubation mol fraction of $0.23 \pm 0.05$. In sum, all of the available evidence suggests that the major effect of liposome incubation is cholesterol depletion and at the very least, it confirms a decrease in the cholesterol : saturated phospholipid ratio. 
Bouma et al. [15] have also observed some specific protein depletion of erythrocytes upon incubation with liposomes. Under the conditions of our liposome incubation, the depletion of membrane associated protein is expected to be less than $1 \%$ of the total (Huestis, W. private communication). In addition, one would expect that protein depletion, even if it were significant, would enhance diI diffusion, since erythrocyte membrane proteins are much less mobile than lipids $[44,45]$. This is the opposite of what is observed. We therefore conclude that alterations in major membrane constituents other than cholesterol (i.e. phospholipids and proteins) are unlikely to account for our results.

The relationship between intermolecular interactions in membranes and lateral diffusion is not well understood on a theoretical molecular level. For the present, we rely on the intuitive idea that cholesterol disorders phospholipid acyl chains at low temperatures, thereby reducing phospholipid-phospholipid interaction energies, leading to a faster molecular lateral diffusion. Our results cannot distinguish between a homogeneous lipid phase or submicroscopic phase separations among which diI might partition unequally. In single-component phosphatidylcholine multilayers, diI does not segregate out either above or below the phase transition [19]. However, we have occasionally observed visible diI fluorescence patches (less than $0.5 \mu \mathrm{m}$ in diameter) only on cholesterol-depleted cells at low temperatures which may be correlated with some lateral phase separation of the lipids and/or diI. In the photobleaching experiments, we avoided these visible diI patches, but it is conceivable that invisible submicroscopic diI aggregations in the observation region could contribute to the slower dil diffusion in cholesterol-depleted cells.

The magnitude of the room temperature diffusion constants for diI in erythrocytes is smaller than those previously reported for diI in certain other cell systems, by factors ranging from about 3 -fold to 10-fold [20-22]. Perhaps part of the difference can be explained by the different methods used to estimate spot radius $w$ on an intensity profile which is never the true Gaussian expected from theory. However, we believe that much of the difference is real, i.e., that diI lateral diffusion rate in our erythrocyte ghosts is indeed slower than in other cell types. In support of this conclusion, we have measured under similar optical conditions the dil diffusion rate in erythrocyte to be slower than in lymphocytes (by a factor of about three) and rat fibroblasts in primary culture (by a factor of about six). This difference may reflect some unique structural feature of the erythrocyte membrane.

One must consider the possibility of artifacts generated by local photobleaching. Local heating is unlikely to cause membrane damage. We have calculated (by the methods of Ref. 46) the maximum temperature rise to be approx. $1^{\circ} \mathrm{C}$ during the $6 \mathrm{~ms}$ bleaching pulse and approx. $0.0001^{\circ} \mathrm{C}$ during observation of fluorescence recovery. However, the possibility of photochemical damage is not as easy to dismiss as heating damage. Jacobson et al. [47] find no scanning electron microscope evidence of damage to locally photobleached tissue culture cells labeled with fluorescein or rhodamine wheat germ agglutinin. On the other hand, other workers have found protein crosslinking induced by prolonged illumination of whole red cells labeled with fluorescein isothiocyanate [48] or fluorescein concanavalin A [49], and eosin- 
sensitized photoinactivation of red cell acetylcholinesterase [50]. Photochemical damage probably depends upon many factors including fluorophore type and location in the membrane, the presence of oxidizing agents, light intensity and duration, illumination area, and cell type. No studies have been reported as yet on the biochemical consequences, if any, of local diI-membrane photobleaching. Nevertheless, we do note that our measured diffusion constants are unchanged with diI concentrations in the membrane ranging over a factor of approximately five. Repetitive bleaching at the same spot usually showed no effect on fluorescence recovery rate; occasionally a rate decrease of at most $30 \%$ was seen after four or five repeated bleachings.

We have shown that cholesterol reduces the dependence of lipid probe lateral diffusion upon temperature; one can argue that cholesterol also reduces the dependence of diffusion upon phospholipid fatty acyl chain composition. Since cholesterol-free phospholipid model systems of different fatty acyl chain compositions have different phase transition temperatures, abolition of the phase transition by cholesterol should also abolish the sensitivity of aspects of the physical state to fatty acyl changes at any temperature. Indeed, fatty acyl changes in one animal cell system have little effect on diI diffusion rate [20]. Perhaps a biological function of cholesterol is to stabilize the physical state of the membrane against changes in temperature or lipid composition.

\section{Acknowledgements}

We thank Dr. Charles Sweeley and Clifford Wong of Michigan State University and Dr. Fred Hoch of the University of Michigan for their generosity, advice, and invaluable help with gas chromatography. We also thank Dr. Alan Waggoner of Amherst College for his gift of diI; Dr. Wray Huestis of Stanford and Dr. Nancy Harvie of the University of Michigan for their helpful advice, Drs. Samuel Krimm and Leon McCaughan of the University of Michigan for their loan of a multichannel analyzer, and Ms. Gloria Adler for typing the manuscript. This work was supported by a University of Michigan Faculty Research Grant; a Research Corporation Cottrell Research Grant; and NINCDS Grant No. 1 R01 NS14565-01.

\section{References}

1 Chapman, D. (1975) Q. Rev. Biophys. 8, 185-235

2 Parce, J.W., Henry, N. and McConnell, H.M. (1978) Proc. Natl. Acad. Sci. U.S.A. 75, 1515-1518

3 Cossins, A.R. and Prosser, C.L. (1978) Proc. Natl. Acad. Sci. U.S.A. 75, 2040-2043

4 Melchior, D.L. and Steim, J.M. (1977) Biochim. Biophys. Acta 466, 148-159

5 Prives, J. and Shinitzky, M. (1977) Nature 268, 761-763

6 Campisi, J. and Scandella, C.V. (1978) Science 199, 1336-1337

7 Johnson, M. and Edidin, M. (1978) Nature 272, 448-450

8 Sandermann, H. (1978) Biochim. Biophys. Acta 515, 209-237

9 Demel, R.A. and DeKruy ff, B. (1976) Biochim. Biophys. Acta 457, 109-132

10 Derzko, Z, and Jacobson, K. (1979) Biophys. J. 25, 172a

11 Cullis, P.R. (1976) FEBS Lett. 70, 223-228

12 Rubenstein, J.L.R., Smth, B.A. and McConnell, H.M. (1979) Proc. Natl. Acad. Sci. U.S.A. 76, 15-18

13 Wu, J., Jacobson, K, and Papahadjopoulos, D. (1977) Biochemistry 16, 3936-3941

14 Bruckdorfer, K.R., Edwards, P.A. and Green, C. (1968) Eur. J. Biochem. 4, 506-511

15 Bouma, S.R., Drislane, F.W. and Huestis, W. (1977) J. Biol. Chem. 252, 6759-6763

16 Grunze, M. and Deuticke, B. (1974) Biochim. Biophys. Acta 356, 125-1 30 
17 Borochov, H. and Shinitzky, M. (1976) Proc. Natl. Acad. Sci. U.S.A. 73, 4526-4530

18 Sims, P.J., Waggoner, A.S., Wang, C.H. and Hoffman, J.F. (1974) Biochemistry 13, 3315-3330

19 Fahey, P.F, and Webb, W.W. (1978) Biochemistry 17, 3046-3053

20 Axelrod, D., Wight, A., Webb, W.W. and Horwitz, A. (1978) Biochemistry 17, 3604-3609

21 Schlessinger, J., Axelrod, D., Koppel, D.E., Webb. W.W. and Elson, E.I. (1977) Science 195, 307309

22 Dragsten, P., Schlessinger, J., Henkart, P., Weinstein, J.N. and Blumenthal, R. (1979) Biophys. J. 25, $294 a$

23 Blumenthal, R., Ralston, E., Dragsten, P. and Weinstein, P.N. (1979) Biophys. J. 25, 291a

24 Axelrod, D., Ravdin, P.M. and Podleski, T.R. (1978) Biochim. Biophys. Acta 511, 23-28

25 Axelrod, D. (1979) Biophys. J. 26, 557-573

26 Axelrod, D., Koppel, D.E., Schlessinger, J., Elson, S. and Webb, W.W. (1976) Biophys. J. 16, 10551069

27 Cooper, R.A., Arner, E.C., Wiley, J.S. and Shattil, S.J. (1975) J. Clin. Invest. 55, 115-126

28 Rose, H.G. and Oklander, M. (1964) J. Lipid Res. 6, 428-431

29 Searcy, R.L., Berquist, L.M. and Jung, R.C. (1960) J. Lipid Res. 1, 348-351

30 Marom, E., Chen, B. and Ramer, O.G. (1979) Opt. Eng. 18, 79-81

31 Raj, T. and Flygare, W.H. (1974) Biochemistry 13, 3336-3340

32 Ladbrooke, R.D., Williams, R.M. and Chapman, D. (1968) Biochim. Biophys. Acta 150, 333-340

33 Brandts, J.F., Taverna, R.D., Sadasivan, E. and Lysko, K.A. (1978) Biochim. Biophys. Acta 512 , $566-578$

34 Dodge, J.T., Mitchell, C. and Hanahan, D.J. (1963) Arch. Biochem. Biophys. 100, 119-130

35 Phillips, M.C. and Finer, E.G. (1974) Biochim. Biophys. Acta 356, 199-206

36 Galla, H.J. and Sackman, E. (1974) Biochim. Biophys. Acta 339, 103-115

37 De Kruyff, B., Van Dijck, P.W.M., Demel, R.A., Scuuijff, A., Brants, F. and Van Deenen, L.L.M. (1974) Biochim. Biophys. Acta 356, 1-7

38 Cooper, R.A., Leslie, M.H., Fischkoff, S., Shinitzky, M. and Shattil, S.J. (1978) Biochemistry 17, $327-331$

39 Shinitzky, M. (1978) FEBS Lett. 85, 317-320

40 Giraud, F. and Claret, M. (1979) FEBS Lett. 103, 186-191

41 Pagano, R.E. and Weinstein, J.N. (1978) Annu. Rev. Biophys. Bioeng. (1978) 7, 435-468

42 Martin, F.J. and MacDonald, R.C. (1976) J. Cell Biol. 70, 515-526

43 Bloj, B. and Zilversmit, D.B. (1977) Biochemistry 16, 3943-3948

44 Peters, R., Peters, J., Tews, K.H. and Bahr, W. (1974) Biochim. Biophys. Acta 367, 282-294

45 Fowler, V. and Branton, D. (1977) Nature 268, 23-26

46 Axelrod, D. (1977) Biophys. J. 18, 129-131

47 Jacobson, K., Hou, Y. and Wojcieszyn, J. (1978) Exp. Cell Res. 116, 179-189

48 Lepock J.R., Thompson, J.E. and Kruuv, J. and Wallach, D.F.H. (1978) Biochem. Biophys. Res. Commun. 85, 344-350

49 Sheetz, M.P. and Koppel, D.E. (1979) Proc. Natl. Acad. Sci. U.S.A. 76, 3314-3317

50 Nigg, E.. Kessler, M, and Cherry, R.J. (1979) Biochim. Biophys. Acta 550, 328-340 